\title{
Comentario Editorial: Fallecimiento del Dr. David Sackett, Presidente Fundador de la Colaboración Cochrane (1934-2015)
}

\author{
Valeria Vietto* y Agustín Ciapponi**
}

Es con gran tristeza que Cochrane anuncia la muerte de su presidente fundador y pionero médico, el Dr. David Sackett, a los 80 años. Nuestros pensamientos y condolencias están con la familia de Dave, amigos y colegas en todo el mundo.

Fue un creador de la epidemiología clínica y de la Medicina basada en la evidencia (MBE) y el primer presidente de la Comisión Directiva de la Colaboración Cochrane en 1993. Fundó el primer departamento de Epidemiología Clínica y Bioestadística en el mundo, en la Universidad McMaster en Hamilton, Ontario (Canadá), en 1967 y fundó el Centro para la MBE en Oxford (Reino Unido) en 1994.

David contribuyó ampliamente al desarrollo de métodos de investigación a través de sus libros y artículos publicados, así como mediante la educación y conferencias en McMaster y en todo el mundo. Cabe destacar que convirtió la investigación clínica en una actividad multidisciplinaria científicamente sólida y en un "deporte de equipo" práctico, lo cual sin duda ha mejorado la calidad de la investigación médica y la práctica clínica. Después de obtener su título de médico en la Universidad de Illinois, Dave pasó a formarse en Nefrología y Medicina Interna, y obtuvo una Maestría en Epidemiología en la Universidad de Harvard. Fue en su momento director médico de los hospitales Chedoke-McMaster y director de la División de Medicina General en la región de Hamilton, Ontario. En el año 2000, fue elegido para el Canadian Medical Hall of Fame, y un año después fue galardonado Officer of the Order de Canadá. En el año 2009 le concedieron el Premio Fundación Gairdner Wightman. Estuvo en diversas ocasiones en España para colaborar con diversas actividades formativas del Centro Cochrane Iberoamericano y de otras entidades.

Se retiró de la práctica clínica en 1999 a la edad de 65 años y regresó a Canadá para establecer un centro de formación en investigación en un lago en el norte del país, donde investigó, escribió y enseñó sobre el desarrollo de ensayos clínicos controlados. Ha publicado 10 libros, capítulos en otros 50 y más de 300 artículos en revistas médicas y científicas.

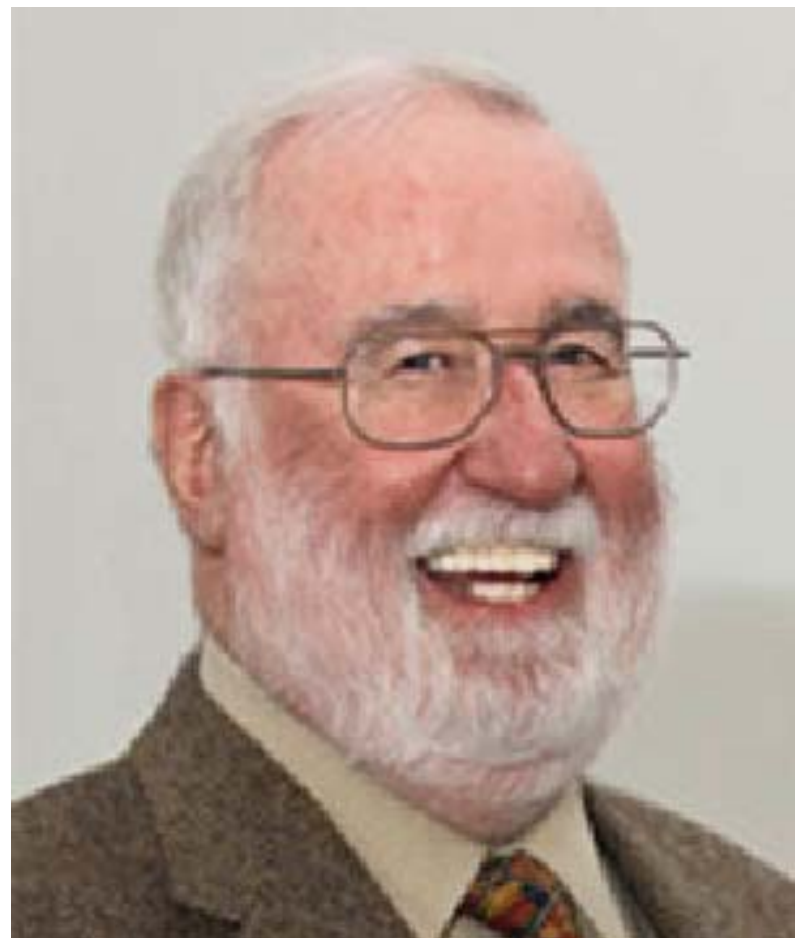

Las contribuciones de Dave al trabajo de Cochrane datan de los primeros días de la organización y han significado un impacto sustancial en su desarrollo y reputación en las últimas dos décadas.

Los colegas de Dave en McMaster y Cochrane tienen previsto conmemorar su contribución a la MBE de diversas formas, incluyendo la celebración del simposio de investigación Dave Sackett y durante el 23ํㅡㄴ Colloquium Cochrane que se celebrará en Viena en octubre de 2015.

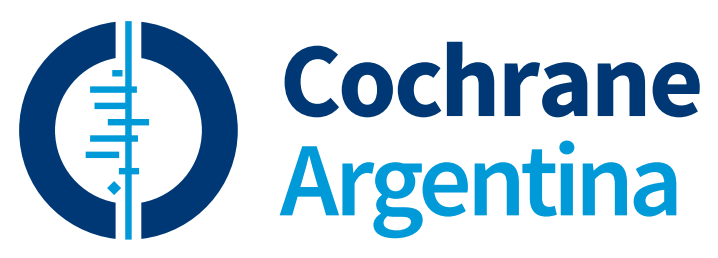

* Centro Cochrane Instituto Universitario del Hospital Italiano de Buenos Aires, Cochrane Argentina valeria.vietto@ hospitalitaliano.org.ar

** Centro Cochrane Instituto de Efectividad Clínica y Sanitaria, Cochrane Argentina agustin.ciapponi@hospitalitaliano.org.ar 